\title{
Fatty Acid Profiles Associated with Microbial Colonization of Freshly Ingested Grass and Rumen Biohydrogenation
}

\author{
E. J. Kim, R. Sanderson, M. S. Dhanoa, and R. J. Dewhurst \\ Institute of Grassland and Environmental Research, Plas Gogerddan, \\ Aberystwyth SY23 3EB, UK
}

\begin{abstract}
Two in situ studies were conducted to examine the use of odd-chain fatty acid profiles to study microbial colonization of freshly ingested herbage in the rumen as well as fatty acid biohydrogenation. In the first study, fresh perennial ryegrass was subjected to a range of sample preparation methods before incubation in the rumen for 2 or $7 \mathrm{~h}$. In the second study, fresh perennial ryegrass was chopped into 1 -cm lengths and incubated in polyester bags in the rumen for 2,8 , and $24 \mathrm{~h}$. After removal of bags from the rumen, 4 different washing methods, ranging from manual squeezing to machine washing, were applied. Fatty acids were extracted from washed residues and determined, as methyl esters, by gas chromatography. The main oddchain fatty acids (with the exception of anteiso $\mathrm{C}_{15: 0}$ ) were not found in fresh grass and were useful markers of the effects of incubation time, sample preparation method, and washing method on microbial colonization/contamination. The concentration of these and other odd-chain fatty acids increased with incubation time in both studies. The results indicate rapid and continued microbial colonization of freshly ingested forages, although patterns of odd-chain fatty acids did not reveal any further information about the types of bacteria-colonizing herbage. Principal component, biplot analysis provided a useful overall description of the processes of microbial colonization and degradation of plant fatty acids on fresh herbage incubated in the rumen. Bolus formation during mastication and ingestion results in extensive damage to herbage; none of the techniques (cutting, crushing, and drying/grinding) investigated in this work was able to replicate the effects of bolus formation in the animal. The study provided further evidence of loss of unfermented feed particles through polyester bag pores, especially when feeds are dried and ground. Biohydrogenation of the polyunsaturated fatty acids of fresh herbage was used
\end{abstract}

Received March 18, 2005.

Accepted May 17, 2005.

Corresponding author: E. J. Kim; e-mail: eun-joong.kim@bbsrc. ac.uk. principally by solid-associated bacteria to enable them to take up high levels of trans- $11 \mathrm{C}_{18: 1}$ and $\mathrm{C}_{18: 0}$ fatty acids. Although trans-11 $\mathrm{C}_{18: 1}$ was strongly associated with bacterial markers (odd- and branched-chain fatty acids), its precursor (cis-9, trans- $11 \mathrm{C}_{18: 2}$ ) was not associated with bacterial variation, suggesting that its production in the rumen under these conditions was mainly extracellular.

(Key words: rumen, odd-chain fatty acid, microbial colonization, polyester bag technique)

Abbreviation key: CLA = conjugated linoleic acid, LAB = liquid-associated bacteria, OBCFA = odd- and branched-chain fatty acids, PCA = principal components analysis, $\mathbf{S A B}=$ solid-associated bacteria, $\mathbf{V A}=$ vaccenic acid.

\section{INTRODUCTION}

It has generally been assumed that the degradation of plant material in the rumen is accomplished by microorganisms. More recently, this assertion has been challenged as studies in vitro have suggested the importance of plant-mediated processes in the period shortly after herbage tissue is cut or damaged (Zhu et al., 1999; Kingston-Smith and Theodorou, 2000). This hypothesis is important, because it offers potential for plant breeding to directly affect critical rumen processes, such as proteolysis and lipolysis, which have a large effect on nutrient utilization and product quality. The central issue for this hypothesis is the relative importance of plant and microbial processes in the degradation of freshly ingested forage. The studies described in this paper used new approaches to address these difficult questions, using multivariate analysis of fatty acid profiles.

Polyester bags are well established as a technique for rumen degradation studies, and their limitations are widely recognized (Dewhurst et al., 1995). Nonetheless, they work best with forages, providing a useful way to separate unfermented fiber from cell solubles that are released after cell damage (Boudon and Peyraud, 2001). Microbial contamination of low-protein forages held in polyester bags has long been recognized 
as a problem when estimating $\mathrm{N}$ degradation (Meyer and Mackie, 1986; Vanzant et al., 1998). However, this effect demonstrates the potential to use the technique in microbial colonization studies. There has been a great deal of debate about which washing procedure to use after removing polyester bags from the rumen (Cherney et al., 1990; Vanzant et al., 1998). Again, the differences between washing techniques in removing bacteria might also be an advantage of the technique, enabling studies of the degree of attachment of rumen microbes.

Alpha-linolenic acid $\left(\mathrm{C}_{18: 3}\right)$ and linoleic acid $\left(\mathrm{C}_{18: 2}\right)$ are the major fatty acids of chloroplast membranes (Hawke, 1973). The major microbial transformations in the rumen are biohydrogenation of $\mathrm{C}_{18: 3}$ and $\mathrm{C}_{18: 2}$, and microbial synthesis of odd- and branched-chain fatty acids (OBCFA). Odd- and branched-chain fatty acids are important components of microbial lipids (O'Kelly and Spiers, 1991). The major OBCFA in rumen microorganisms and milk are pentadecanoic acid $\left(\mathrm{C}_{15: 0}\right)$, heptadecanoic acid $\left(\mathrm{C}_{17: 0}\right)$, iso $\mathrm{C}_{15: 0}$ (13-methyltetradecanoic acid), anteiso $\mathrm{C}_{15: 0}$ (12-methyl-tetradecanoic acid), iso $\mathrm{C}_{17: 0}$ (15-methyl-hexadecanoic acid), and anteiso $\mathrm{C}_{17: 0}$ (14-methyl-hexadecanoic acid) (Fievez et al., 2003). These fatty acids are generally rare or absent from feeds (Diedrich and Henschel, 1990), although this was evaluated further in this work. Because the patterns of OBCFA vary between species (Dzierzewicz et al., 1996; Zelles, 1997) and functional groups (Lee et al., 1999) of rumen microorganisms, it is even possible that these fatty acids could provide a qualitative description of the rumen microbial population. Previous studies (Massart-Leen and Massart, 1981; Cabrita et al., 2003; Fievez et al., 2003) have used factor analysis to identify groups of fatty acids with similar variation across samples to identify common metabolic pathways.

The primary objective of this work was to investigate the use of odd-chain fatty acids as markers of microbial colonization of fresh herbage. Multivariate statistical approaches have been adopted to aid in the interpretation of complex fatty acid profiles. A second objective of these studies was to gain insight into the mechanisms that lead to increased levels of biohydrogenation intermediates-particularly conjugated linoleic acids (CLA) in milk and meat from grazing ruminants (see references cited by Dewhurst and Lee, 2005).

\section{MATERIALS AND METHODS}

\section{Animals and Their Management}

Experiments were conducted under the authority of licenses of the UK Animal Scientific Procedures Act (1986). These experiments used Holstein-Friesian dairy cows that had previously been prepared with rumen cannulae (Bar-Diamond, Parma, ID). The cows were nonpregnant and nonlactating and grazed a ryegrass sward prior to and during the experiments. Samples of grass were cut from the field using mechanical shears held at $5 \mathrm{~cm}$ above ground level. Samples were placed in cool boxes and transferred to the animal house for preparation (within $10 \mathrm{~min}$ ) and incubation in the rumen (within an additional $45 \mathrm{~min}$ ). Liquidassociated bacteria (LAB) and solid-associated bacteria (SAB) were isolated from rumen contents taken at rumen emptying (Experiment 1; see below) or at the same times that bags were removed from cows (Experiment 2; see below) using the differential centrifugation procedures described by Siddons et al. (1982).

\section{Polyester Bag Experiments}

The polyester bags used for this study had dimensions of $22 \times 9 \mathrm{~cm}$ and were made from material with a mesh opening of $55 \mu \mathrm{m}$ and an open area of $27 \%$. Polyester bags were incubated in the rumen attached to $50-\mathrm{cm}$ semi-flexible stalks that retained bags within the liquid phase of rumen contents. The first experiment investigated effects of herbage preparation methods prior to incubation; the second experiment investigated effects of different washing procedures after incubation.

Experiment 1. Perennial ryegrass (Lolium perenne cv. Fennema) that had regrown for $3 \mathrm{wk}$ and was harvested at 0800 h on September 25, 2001, was used for this work. Seven different methods of sample preparation were investigated: method 1 , no further processing: grass was gently folded and placed into polyester bags; method 2, chopping into approximately $1-\mathrm{cm}$ lengths using scissors; method 3, crushing between rollers so that plant tissue was visibly damaged, but not chopping; method 4, chopping and crushing-a combination of methods 2 and 3; method 5, chopping $1 \mathrm{~kg}$ of grass with a mechanical food-chopping device (Lynhakker GH33; George Hansen, Copenhagen, Denmark) for $30 \mathrm{~s}$; method 6 , ingested boli; and method 7, freeze-dried and ground ryegrass (prepared from the same plot, but harvested $2 \mathrm{~d}$ earlier). Approximately one-half of the rumen contents was temporarily removed to permit collection of ingested boli (approximately $1 \mathrm{~kg}$ of fresh weight) as they entered the rumen at the end of the esophagus. Rumen contents were returned to cows prior to incubation of polyester bags.

Samples (approximately $7 \mathrm{~g}$ of $\mathrm{DM}$ ) were weighed into preweighed polyester bags and inserted into the rumen. Duplicates of each treatment were incubated in each of 2 cows for both 2 - and 7-h periods. The cows returned to graze pasture while the bags were 
incubated. Following removal from the cows, the bags were gently rinsed in a sink full of water (repeating until there was no further visible loss of bag contents) and immediately frozen at $-20^{\circ} \mathrm{C}$. These samples, as well as samples of the fresh herbage, were subsequently freeze-dried, ground through a 1-mm screen, and analyzed for fatty acid content.

Experiment 2. Perennial ryegrass (Lolium perenne cv. Fennema) that had regrown for $3 \mathrm{wk}$ and was harvested at 0800 on August 29, 2001, was cut from the field and immediately chopped into 1-cm lengths using scissors. Approximately $7 \mathrm{~g}$ of DM were weighed into polyester bags, and 8 bags were incubated in each of 2 cows for 2,8 , and $24 \mathrm{~h}$. Upon removal of bags from the rumen, duplicate bags from each cow were washed according to one of 4 washing procedures: washing method 1 , squeezing of the bag and its contents so that no more liquid ran out; washing method 2 , gentle hand washing by agitating bags and their contents in a sink of cold water, repeating until there was no further visible loss of bag contents; washing method 3 , hand washing under a continuous stream of cold water until the water ran clear; and washing method 4 , machine washing in cold water (involving 4 rinse cycles with agitation for $1 \mathrm{~min}$ and a final spin for $2 \mathrm{~min}$ ) then immediate freezing at $-20^{\circ} \mathrm{C}$. These samples, as well as samples of the fresh herbage, were subsequently freeze-dried, ground through a 1-mm screen, and submitted for fatty acid analysis.

\section{Chemical Analyses}

The methods used for chemical analysis of feeds and polyester bag residues in our laboratory have been described previously (Dewhurst et al., 2003). The analysis of fatty acid content in samples of herbage, polyester bag residues, and bacterial fractions used the direct transesterification method of Sukhija and Palmquist (1988). The internal standard $\left(\mathrm{C}_{23: 0}\right.$; tricosanoic acid) was added before methylation, and fatty acid methyl esters were analyzed by gas liquid chromatography (CP-3800; Varian Ltd., Walton-on-Thames, UK) on a CP Sil 88 fatty acid methyl esters column $(100 \mathrm{~m} \times$ $0.25 \mathrm{~mm}$ i.d., Cat. no. CP7489; Varian UK Ltd., Surrey, UK) with split injection (injection volume of $1 \mu \mathrm{L}$ at 1:30 split ratio). The temperature of injector and detector were maintained at 250 and $255^{\circ} \mathrm{C}$, respectively. The initial oven temperature was $70^{\circ} \mathrm{C}$ (held for $1 \mathrm{~min}$ ) and increased by $5^{\circ} \mathrm{C} / \mathrm{min}$ to $100^{\circ} \mathrm{C}$ (held for $2 \mathrm{~min}$ ), then increased at $10^{\circ} \mathrm{C} / \mathrm{min}$ to $175^{\circ} \mathrm{C}$ (held for $40 \mathrm{~min}$ ), and increased by $5^{\circ} \mathrm{C} / \mathrm{min}$ to a final temperature of $225^{\circ} \mathrm{C}$ (held for $15 \mathrm{~min}$ ). Peaks were identified from standards and quantified using the internal standard.

\section{Statistical Procedures}

All statistical analyses used the Genstat package (Genstat Release 7.1; Lawes Agricultural Trust, 2002). Fatty acid concentrations in LAB and SAB were compared using one-way ANOVA; there was no significant effect of sampling time in experiment 2. Dry matter and $\mathrm{N}$ disappearances from polyester bags were subjected to ANOVA using the REML procedure. The treatment factors were processing technique (experiment 1) or washing technique (experiment 2), time, and their interactions. Pooled SEM are shown in Figure 1 . The same statistical models were used to analyze effects on concentrations of individual fatty acids in polyester bag residues.

Further analysis of fatty acid profiles in polyester bag residues use principal component analysis (PCA) in conjunction with the biplot procedure of Genstat 7.1. Principal component analysis provides linear combinations of a set of variables that maximize the variation contained within them, displaying most of the original variability in a smaller number of dimensions (Jolliffe, 1986). To visualize both the principal component coefficients for each variable and the principal component scores for each observation, the results from the PCA were subjected to the biplot procedure (Gabriel, 1971). The direction and length of the vector indicate how each variable contributes to the first 2 principal components in the figure (Figures 4 and 5).

\section{RESULTS}

The chemical composition of the grass used in each of the experiments is shown in Table 1; values are typical for a short regrowth of perennial ryegrass. Fatty acid analysis is presented in Tables 1 (grass samples) and 2 (LAB and SAB isolated from rumen samples). Alpha-linolenic and linoleic acids were the predominant fatty acids in fresh forage (69 and $12 \%$ of totals, respectively), but were virtually absent from $\mathrm{LAB}$ and SAB.

Rumen degradabilities of DM and $\mathrm{N}$ are shown in Figure 1. For each experiment, there was the anticipated, highly significant increase in rumen degradation within increasing rumen incubation time $(P<$ 0.001). Treatments (processing and washing methods) also had highly significant effects on DM and $\mathrm{N}$ degradation $(P<0.001)$, but there were no treatment $\times$ time interactions $(P>0.05)$. Intact grass (processing method 1) was hardly degraded by $2 \mathrm{~h}$ of rumen incubation, but fresh bolus (processing method 6) and freezedried and ground samples (processing method 7) were degraded extensively (Figure 1a). Similarly, DM disappearance was much greater with mechanical wash- 
$\mathbf{a}$

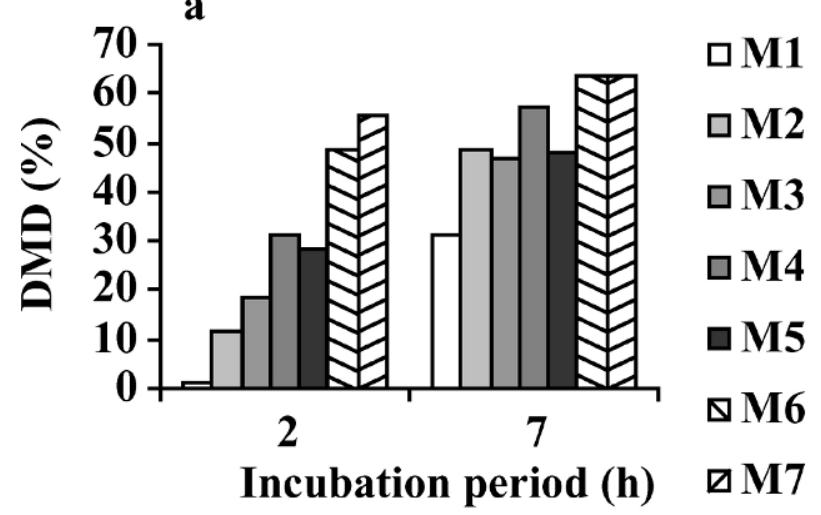

$\mathbf{b}$
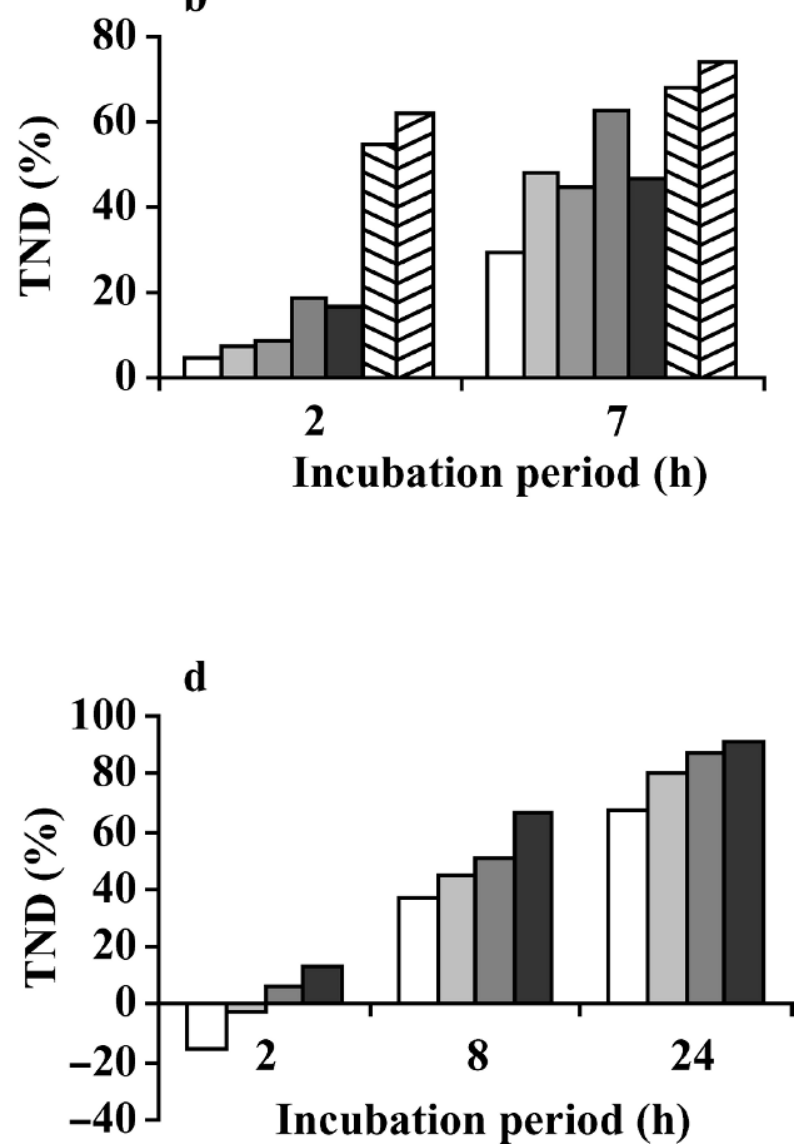
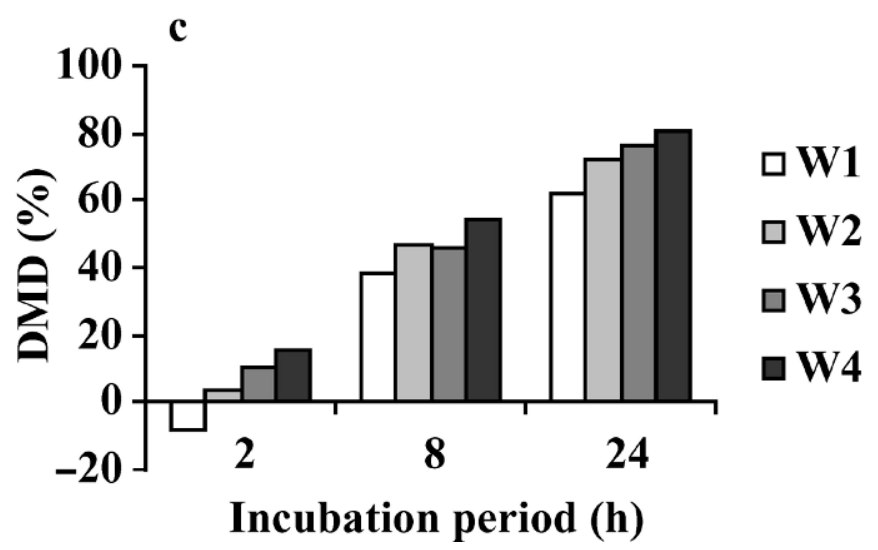

Figure 1. Apparent degradation of DM (DMD) and total N (TND) from polyester bags incubated in the rumen of dairy cows for varying periods, according to sample preparation technique (experiment 1; a and b) or bag washing technique (experiment 2; c and d). Pooled SEM for DMD and TND were 3.10 and 3.98, respectively, for experiment 1 and 4.35 and 4.74, respectively, for experiment 2 . M = processing method. Method 1 (M1), no further processing: grass was gently folded and placed into polyester bags; method 2 (M2), chopping into approximately 1-cm lengths using scissors; method 3 (M3), crushing between rollers so that plant tissue was visibly damaged, but not chopping; method 4 (M4), chopping and crushing-a combination of M2 and M3; method 5 (M5), chopping 1 kg of grass with a mechanical food-chopping device (Lynhakker GH33; George Hansen, Copenhagen, Denmark) for 30 s; method 6 (M6), ingested boli; and method 7 (M7), freeze-dried and ground ryegrass (prepared from the same plot, but harvested $2 \mathrm{~d}$ earlier). W = washing method. Washing method 1 (W1), squeezing of the bag and its contents so that no more liquid ran out; washing method 2 (W2), gentle hand washing by agitating bags and their contents in a sink of cold water, repeating until there was no further visible loss of bag contents; washing method 3 (W3), hand washing under a continuous stream of cold water until the water ran clear; and washing method 4 (W4), machine washing in cold water (involving 4 rinse cycles with agitation for $1 \mathrm{~min}$ and a final spin for $2 \mathrm{~min}$ ) then immediate freezing at $-20^{\circ} \mathrm{C}$.

ing compared with hand washing or squeezing (Figure 1c).

Results of fatty acid concentrations in polyester bag residues are presented in Figures 2 and 3. In general, concentrations of the plant-derived fatty acids ( $\alpha$-linolenic and linoleic acids) decreased with increasing duration of rumen incubation $(P<0.001)$; the microbially derived OBCFA generally increased $(P<0.001)$. However, there was no change over time in the concentrations of $\alpha$-linolenic and linoleic acids for the unprocessed herbage (processing method 1) and only a small decrease for material, which was lightly processed (processing method 2). Nonetheless, concentrations of trans-11 $\mathrm{C}_{18: 1}$ increased for all treatments. There were some exceptions to the increasing concentrations of OBCFA with time, notably the small changes for most OBCFA with material prepared using the mechanical chopper (processing method 5). This situation was mirrored with the sample preparation and residue washing techniques that affected the apparent degradation of plant fatty acids and apparent microbial colonization. The picture was less clear for anteiso $\mathrm{C}_{15: 0}$ in experiment 1 , presumably a reflection of the fact that the grass had a significant level of this fatty acid.

The patterns of change in plant and microbial fatty acids were investigated further using PCA biplot analysis, and results are presented in Figure 4 (experiment 1) and 5 (experiment 2). Each vector (its direction) 
Table 1. Chemical composition of the fresh forage (perennial ryegrass) used for each experiment (\% of DM unless otherwise stated).

\begin{tabular}{lcc}
\hline Chemical composition & Experiment 1 & Experiment 2 \\
\hline Oven DM (\%) & 12.5 & 10.8 \\
OM & 90.7 & 88.8 \\
Total N & 3.18 & 3.55 \\
$\mathrm{NDF}$ & 42.0 & 40.9 \\
$\mathrm{ADF}$ & 22.4 & 24.0 \\
Water-soluble carbohydrate & 18.1 & 13.5 \\
Fatty acids composition & & \\
iso $\mathrm{C}_{15: 0}$ & 0.001 & $\mathrm{ND}^{1}$ \\
anteiso $\mathrm{C}_{15: 0}$ & 0.198 & 0.021 \\
$\mathrm{C}_{15: 0}$ & 0.002 & $\mathrm{ND}$ \\
$\mathrm{C}_{16: 0}$ & 0.391 & 0.457 \\
iso $\mathrm{C}_{17: 0}$ & 0.001 & $\mathrm{ND}$ \\
anteiso $\mathrm{C}_{17: 0}$ & 0.003 & $\mathrm{ND}$ \\
$\mathrm{C}_{17: 0}$ & 0.003 & 0.003 \\
$\mathrm{C}_{18: 0}$ & 0.038 & 0.038 \\
$\mathrm{C}_{18: 1}$ trans-11 & $\mathrm{ND}$ & $\mathrm{ND}$ \\
$\mathrm{C}_{18: 2}$ cis- 9, trans-11 & $\mathrm{ND}$ & $\mathrm{ND}$ \\
$\mathrm{C}_{18: 2}$ n-6 & 0.358 & 0.465 \\
$\mathrm{C}_{18: 3}$ n-3 & 2.018 & 2.82 \\
Total fatty acids & 3.08 & 3.91 \\
\hline
\end{tabular}

${ }^{1} \mathrm{ND}=$ Not detected.

indicates a fatty acid, and different shapes of symbols indicate either sample preparations (Figure 4) or washing techniques (Figure 5). The symbol fill repre- sents the incubation period. Overall, the PCA-biplot analysis procedure simultaneously showed variation in fatty acids and the effects of treatments on that variation. The first 2 principal components accounted for 69.4 and $16.7 \%$, respectively, of the total variability in the profiles in experiment 1 , and 67.2 and $19.7 \%$, respectively, in experiment 2 .

\section{DISCUSSION}

\section{Fatty Acid Profiles of Herbage and Bacteria}

The first requirement for a marker of rumen microbial synthesis is that it is found in rumen microbes, but not in feeds. The presence of appreciable levels of anteiso $\mathrm{C}_{15: 0}$ in one of the grass samples precludes its use as a microbial marker. The unusually high levels of this fatty acid were not proportionate to levels of other OBCFA, suggesting that it was not a result of contamination by epiphytic bacteria, which would contain all of the OBCFA. The problem with this fatty acid was also seen in the way that it behaved differently from other OBCFA in the PCA-biplot analysis (Figure 5). Fresh grass also contained detectable, but very low, levels of $\mathrm{C}_{15: 0}$, and $\mathrm{C}_{17: 0}$. The other OBCFA

Table 2. Comparison of the fatty acid composition of liquid-associated bacteria (LAB) and solid-associated bacteria (SAB) from the 2 experiments $(\%$ of $\mathrm{DM})$.

\begin{tabular}{|c|c|c|c|c|}
\hline & LAB & $\mathrm{SAB}$ & SEM & Significance \\
\hline $\begin{array}{l}\text { Experiment } 1(\mathrm{n}=2) \\
\text { iso } \mathrm{C}_{15: 0} \\
\text { anteiso } \mathrm{C}_{15: 0} \\
\mathrm{C}_{15: 0} \\
\mathrm{C}_{16: 0} \\
\text { iso } \mathrm{C}_{17: 0} \\
\text { anteiso } \mathrm{C}_{17: 0} \\
\mathrm{C}_{17: 0} \\
\mathrm{C}_{18: 0} \\
\mathrm{C}_{18: 1} \text { trans- } 11 \\
\mathrm{C}_{18: 2} \text { cis-9, trans-11 } \\
\mathrm{C}_{18: 2} n-6 \\
\mathrm{C}_{18: 3} n-3 \\
\text { Total fatty acids }\end{array}$ & $\begin{array}{l}0.129 \\
0.349 \\
0.232 \\
1.216 \\
0.036 \\
0.131 \\
0.059 \\
4.21 \\
0.115 \\
0.008 \\
0.104 \\
0.105 \\
7.10\end{array}$ & $\begin{array}{c}0.105 \\
0.221 \\
0.287 \\
2.006 \\
0.059 \\
0.188 \\
0.103 \\
10.41 \\
0.339 \\
0.006 \\
0.129 \\
0.141 \\
14.46\end{array}$ & $\begin{array}{l}0.0015 \\
0.0144 \\
0.0154 \\
0.1157 \\
0.0032 \\
0.0018 \\
0.0020 \\
0.560 \\
0.0384 \\
0.0005 \\
0.0111 \\
0.0170 \\
0.682\end{array}$ & $\begin{array}{l}* \\
* \\
\mathrm{NS} \\
* \\
* \\
* * \\
* * \\
* \\
* \\
\dagger \\
\mathrm{NS} \\
\mathrm{NS} \\
*\end{array}$ \\
\hline $\begin{array}{l}\text { Experiment } 2(\mathrm{n}=6) \\
\text { iso } \mathrm{C}_{15: 0} \\
\text { anteiso } \mathrm{C}_{15: 0} \\
\mathrm{C}_{15: 0} \\
\mathrm{C}_{16: 0} \\
\text { iso } \mathrm{C}_{17: 0} \\
\text { anteiso } \mathrm{C}_{17: 0} \\
\mathrm{C}_{17: 0} \\
\mathrm{C}_{18: 0} \\
\mathrm{C}_{18: 1} \text { trans- } 11 \\
\mathrm{C}_{18: 2} \text { cis-9, trans-11 } \\
\mathrm{C}_{18: 2} n-6 \\
\mathrm{C}_{18: 3} n-3 \\
\text { Total fatty acids }\end{array}$ & $\begin{array}{l}0.157 \\
0.405 \\
0.245 \\
1.214 \\
0.036 \\
0.110 \\
0.051 \\
2.08 \\
0.142 \\
\mathrm{ND}^{1} \\
0.131 \\
0.133 \\
5.20\end{array}$ & $\begin{array}{c}0.103 \\
0.179 \\
0.265 \\
2.123 \\
0.056 \\
0.168 \\
0.102 \\
11.0 \\
0.969 \\
0.007 \\
0.158 \\
0.190 \\
15.90\end{array}$ & $\begin{array}{l}0.0040 \\
0.0156 \\
0.0127 \\
0.0659 \\
0.0029 \\
0.0063 \\
0.0032 \\
0.477 \\
0.0962 \\
0.0003 \\
0.0076 \\
0.0081 \\
0.636\end{array}$ & $\begin{array}{l}* * * \\
* * * \\
\mathrm{NS} \\
* * * \\
* * * \\
* * * \\
* * * \\
* * * \\
* * * \\
* * * \\
* \\
* * * \\
* * *\end{array}$ \\
\hline
\end{tabular}

${ }^{1} \mathrm{ND}=$ Not detected.

$\dagger P \leq 0.10 ; * P \leq 0.05 ; * * P \leq 0.01 ; * * * P \leq 0.001$ 

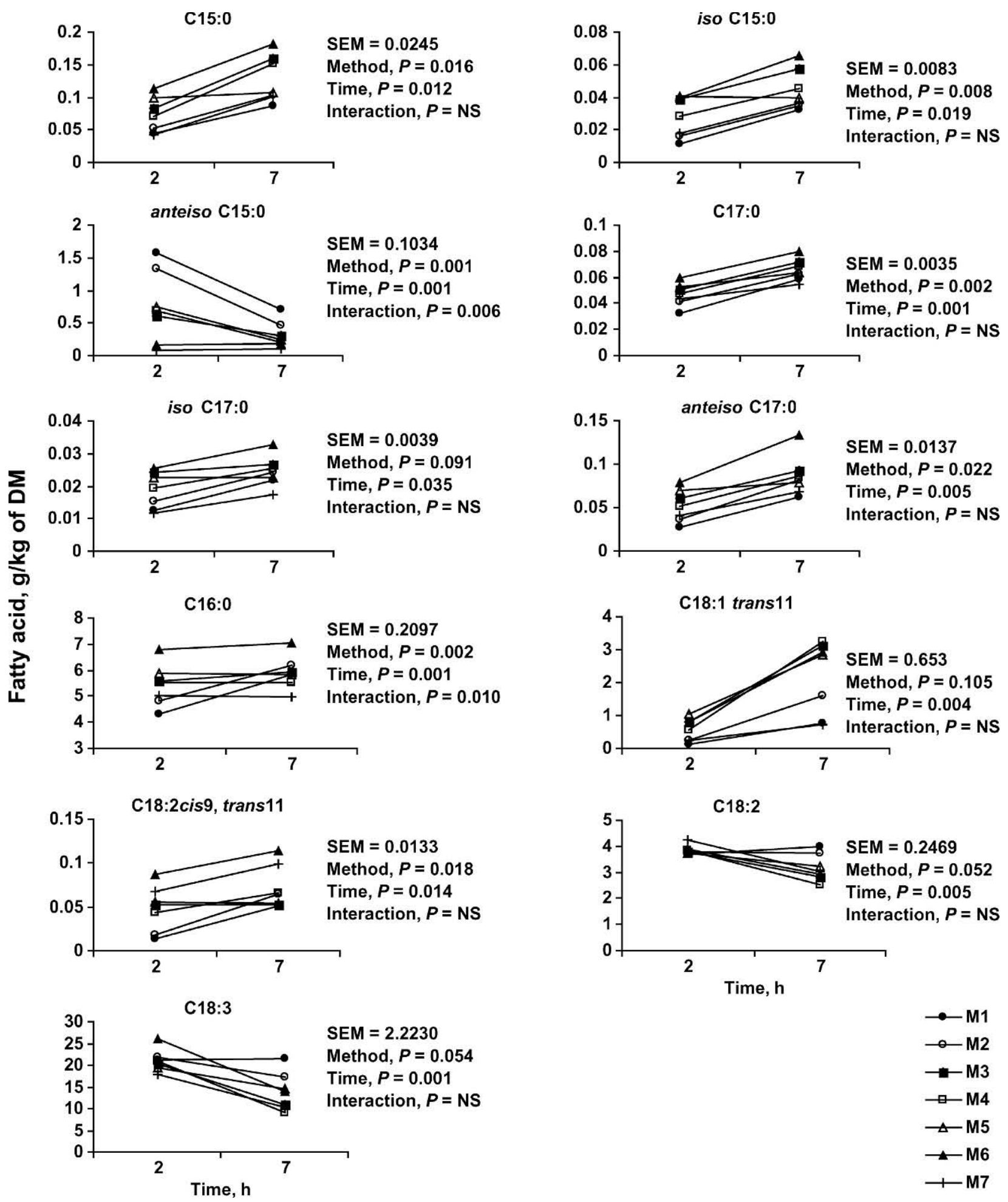

Figure 2. Relationships between the concentration (Y-axis; $\mathrm{g} / \mathrm{kg}$ of $\mathrm{DM}$ ) of fatty acids from polyester bag residues and incubation period (X-axis; time expressed in hours) (experiment 1). $\mathrm{M}$ = processing method. Method 1 (M1), no further processing: grass was gently folded and placed into polyester bags; method 2 (M2), chopping into approximately 1-cm lengths using scissors; method 3 (M3), crushing between rollers so that plant tissue was visibly damaged, but not chopping; method 4 (M4), chopping and crushing-a combination of M2 and M3; method 5 (M5), chopping $1 \mathrm{~kg}$ of grass with a mechanical food-chopping device (Lynhakker GH33; George Hansen, Copenhagen, Denmark) for $30 \mathrm{~s}$; method 6 (M6), ingested boli; and method 7 (M7), freeze-dried and ground ryegrass (prepared from the same plot, but harvested $2 \mathrm{~d}$ earlier $) . \mathrm{NS}=$ Not significant $(P>0.05)$. 
KIM ET AL.

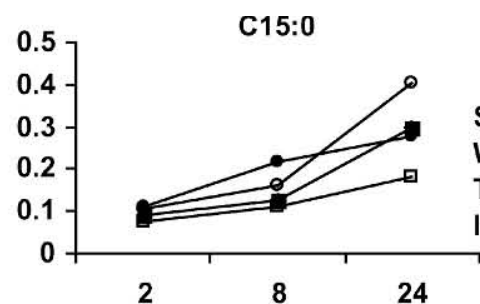

SEM $=0.0763$

Washing, $P<0.001$

Time, $P=0.013$

Interaction, $P=0.002$

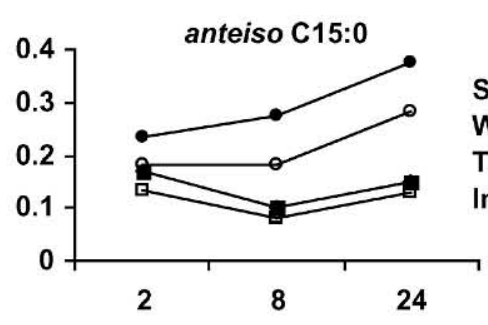

SEM $=\mathbf{0 . 0 1 6 3}$

Washing, $P<0.001$

Time, $P<0.001$

Interaction, $P<0.001$

\section{(5)}

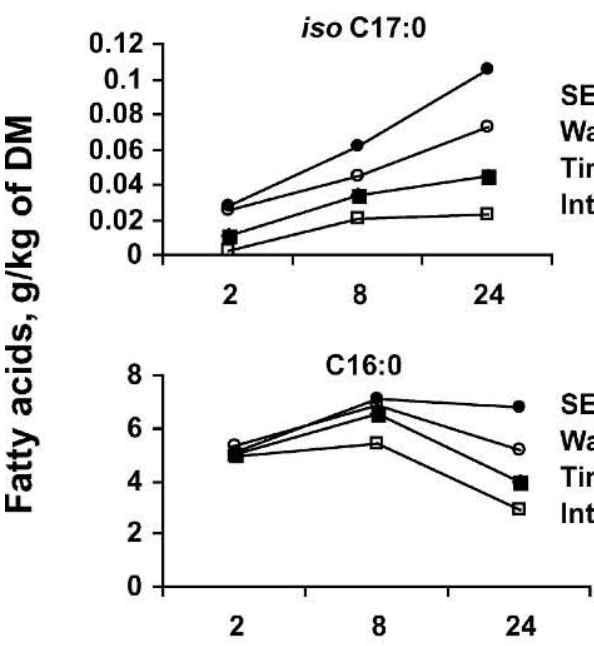

SEM $=\mathbf{0 . 0 0 6 4}$

Washing, $P<0.001$

Time, $P<0.001$

Interaction, $P<0.001$

SEM $=0.1848$

Washing, $P<0.001$

Time, $P<0.001$

Interaction, $P<0.001$

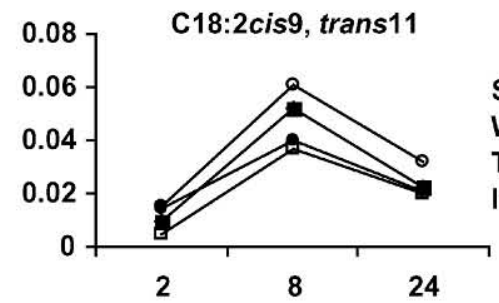

SEM $=0.0031$

Washing, $P<0.001$

Time, $P<0.001$

Interaction, $P=0.006$

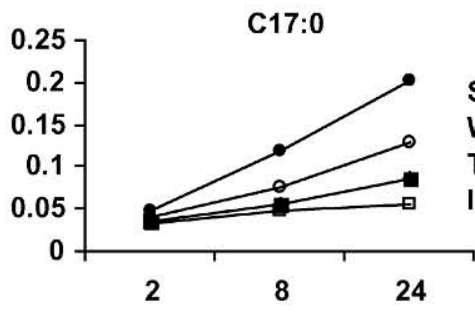

SEM $=0.0134$

Washing, $P<0.001$

Time, $P<0.001$

Interaction, $P<0.001$
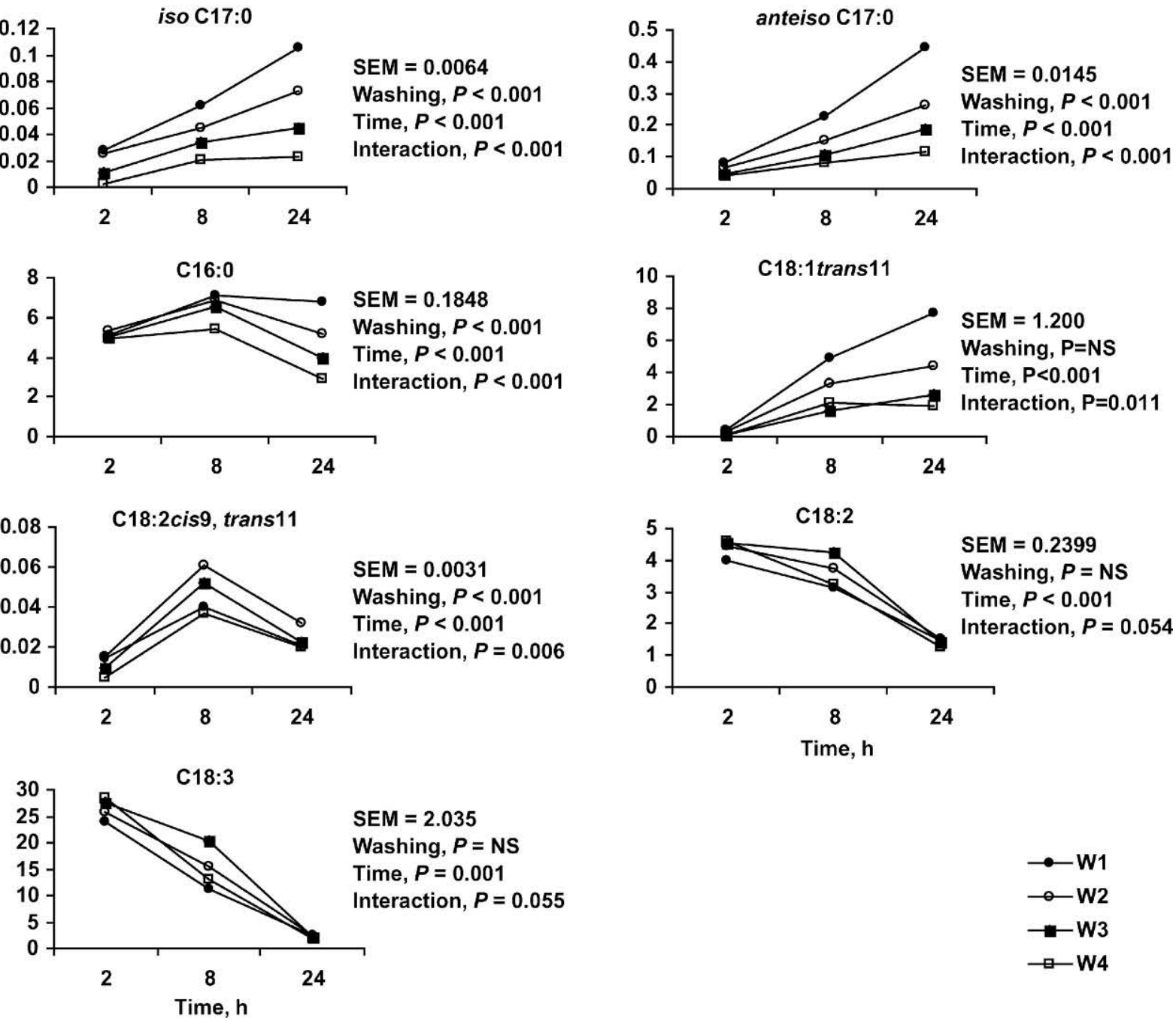

SEM $=2.035$

Washing, $P=$ NS

Time, $P=0.001$

Interaction, $P=0.055$

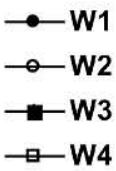

Time, h

Figure 3. Relationships between the concentration (Y-axis; g/kg of DM) of fatty acids from polyester bag residues and incubation period (X-axis; time expressed in hours) (experiment 2). $\mathrm{W}$ = washing method. Washing method 1 (W1), squeezing of the bag and its contents so that no more liquid ran out; washing method 2 (W2), gentle hand washing by agitating bags and their contents in a sink of cold water, repeating until there was no further visible loss of bag contents; washing method 3 (W3), hand washing under a continuous stream of cold water until the water ran clear; and washing method 4 (W4), machine washing in cold water (involving 4 rinse cycles with agitation for 1 $\min$ and a final spin for $2 \mathrm{~min})$ then immediate freezing at $-20^{\circ} \mathrm{C}$. NS $=$ Not significant $(P>0.05)$. 


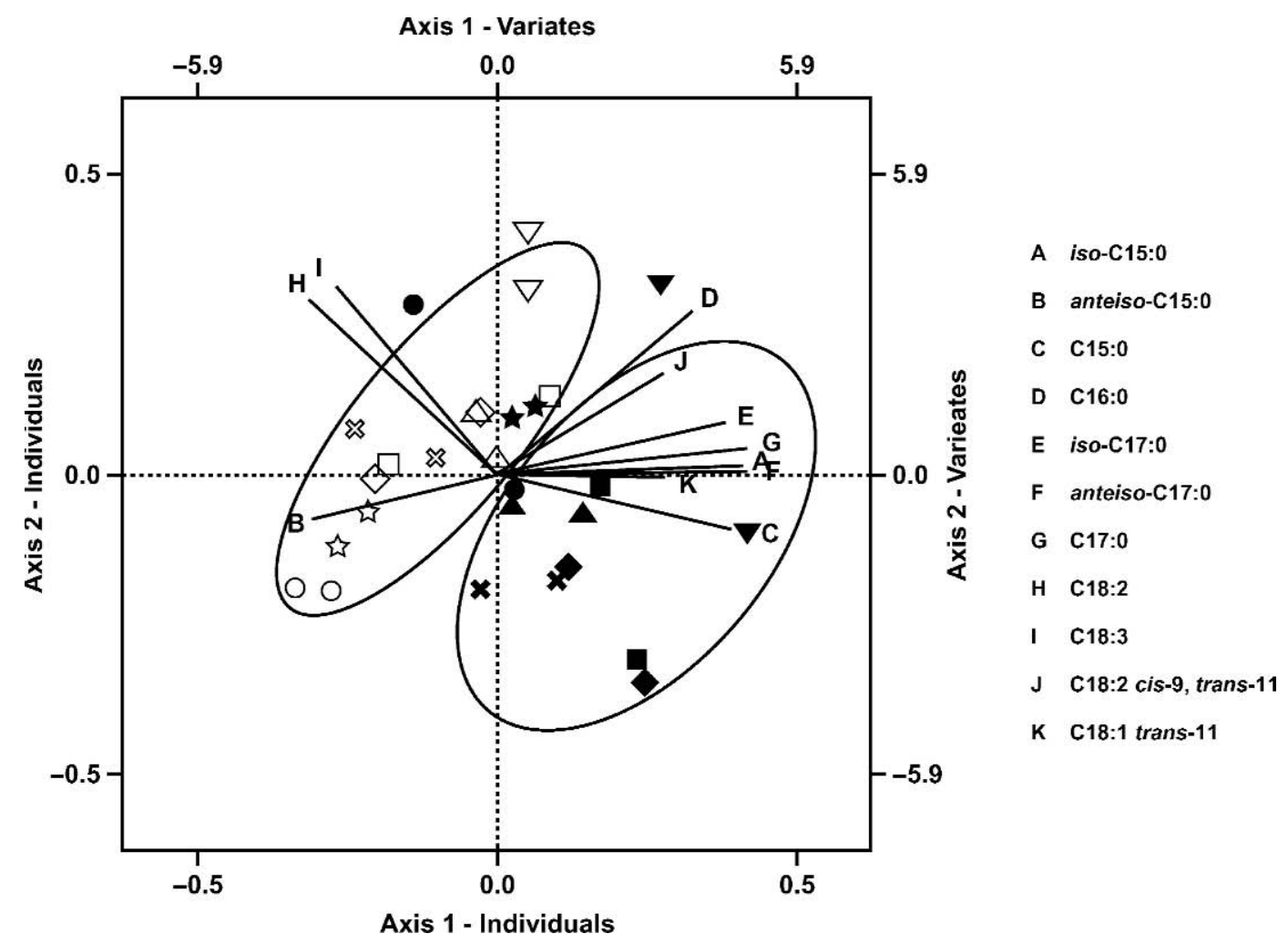

Figure 4. Principal component analysis-biplot analysis showing the relationship between treatments and selected fatty acids for experiment 1. Open and closed symbols are 2- and 7-h incubations, respectively. Sample preparation treatments are indicated by symbol shapes: method $1(\bullet)$, no further processing: grass was gently folded and placed into polyester bags; method 2 ( $\star$ ), chopping into approximately 1-cm lengths using scissors; method $3(\mathbf{\square})$, crushing between rollers so that plant tissue was visibly damaged, but not chopping; method 4 ( ), chopping and crushing - a combination of methods 2 and 3; method 5 ( food-chopping device (Lynhakker GH33; George Hansen, Copenhagen, Denmark) for $30 \mathrm{~s}$; method 6 ( $\mathbf{\nabla})$, ingested boli; and method 7 ( $\boldsymbol{*}$ ), freeze-dried and ground ryegrass (prepared from the same plot, but harvested $2 \mathrm{~d}$ earlier).

were not detected. These are more appropriate as rumen microbial markers.

Total fatty acid concentrations were much higher in $\mathrm{SAB}$ than in LAB, in agreement with earlier studies (Merry and McAllan, 1983; Bauchart et al., 1990). A large part of this difference is explained by increased levels of $\mathrm{C}_{18: 0}$ in SAB. Levels of vaccenic acid (VA; trans-11 $\mathrm{C}_{18: 1}$ ) were also 3 to 5 times higher in $\mathrm{SAB}$ than in LAB. This confirms that SAB are the predominant biohydrogenators in the rumen and that biohydrogenation ability is associated with ability to take up VA and $\mathrm{C}_{18: 0}$. There were consistent differences in bacterial OBCFA profiles; SAB contained higher concentrations of the $\mathrm{C} 17$ fatty acids and lower concentrations of anteiso $\mathrm{C}_{15: 0}$ on a $\mathrm{DM}$ basis.

\section{Fatty Acid Profiles After Rumen Incubations}

The increase in concentrations of individual OBCFA in experiments 1 (except for anteiso $\mathrm{C}_{15: 0}$ ) and 2 clearly demonstrated rapid and continued microbial coloniza- tion (or contamination) of freshly ingested forages, regardless of treatments. These increases were accompanied by a concurrent decrease in concentrations of the plant-derived fatty acids ( $\alpha$-linolenic and linoleic acids). This effect is evident in the opposing vectors for these groups of fatty acids in the PCA-biplot analysis figures (Figures 4 and 5). Palmitic acid $\left(\mathrm{C}_{16: 0}\right)$, which is present in both herbage and bacteria (Table 2), varied according to a pattern that was generally intermediate to the pattern for plant-derived fatty acids $\left(\mathrm{C}_{18: 2}\right.$ and $\mathrm{C}_{18: 3}$ ) and to that for the microbially derived OBCFA, reflecting its dual origin. The PCA-biplot analysis procedure provides an overall description of the changes in fatty acid profiles in a single image. Samples that are closest together show similar patterns of change in their fatty acid profiles. Consequently, it is possible to use this approach to define the sample preparation procedure that most closely mimicked the natural process of bolus formation during ingestion and mastication. It is particularly interesting to compare sample preparation techniques after $2 \mathrm{~h}$ of incubation (open 


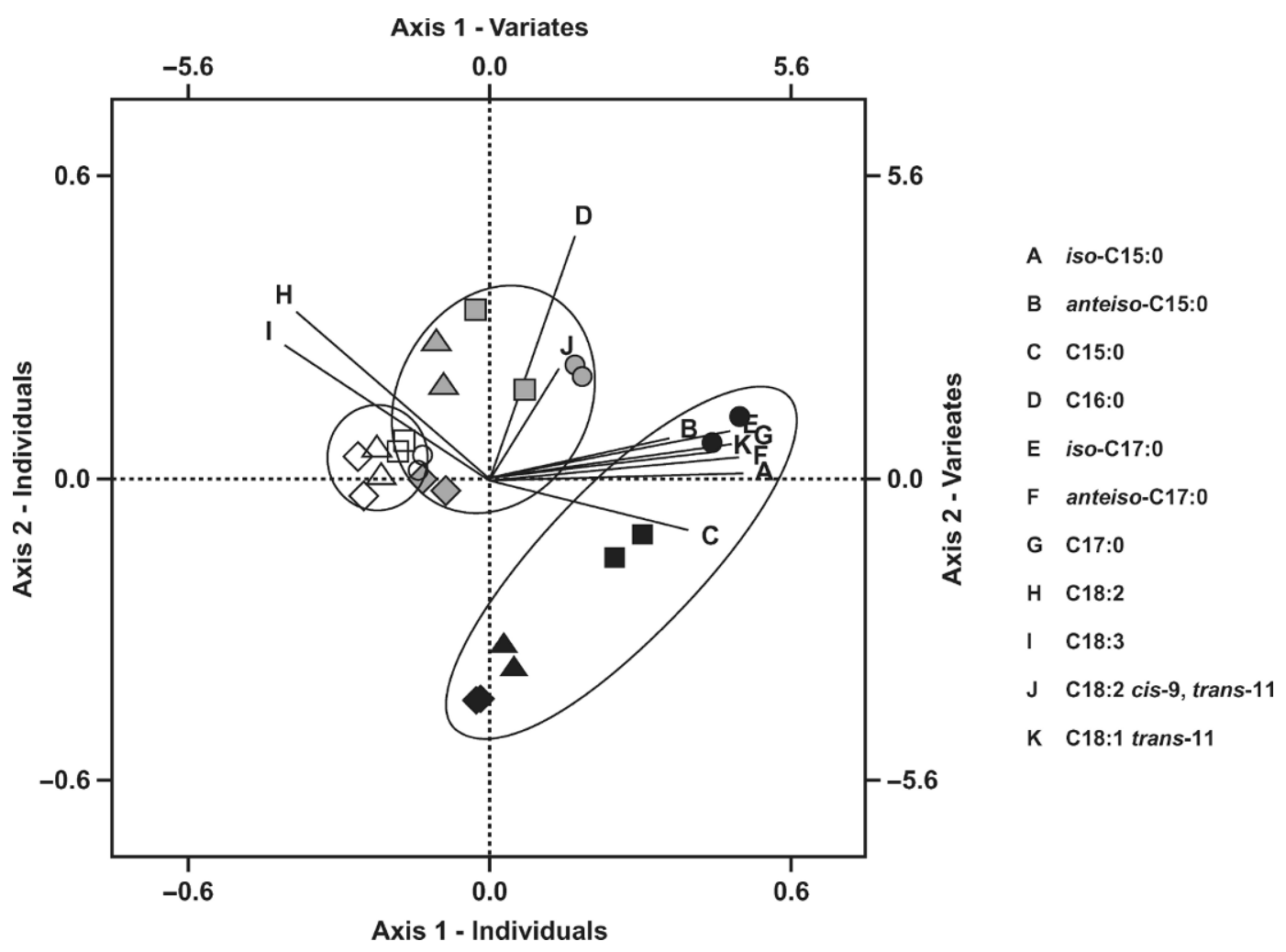

Figure 5. Principal component analysis-biplot analysis showing the relationship between treatments and selected fatty acids for experiment 2. Open shaded, and closed symbols are for 2- 8-, and 24-h incubation periods, respectively. Bag washing treatments are indicated by symbol shapes: washing method $1(\bullet)$, squeezing of the bag and its contents so that no more liquid ran out; washing method 2 (匹), gentle hand washing by agitating bags and their contents in a sink of cold water, repeating until there was no further visible loss of bag contents; washing method $3(\mathbf{\Delta})$, hand washing under a continuous stream of cold water until the water ran clear; and washing method $4(\bullet)$, machine washing in cold water (involving 4 rinse cycles with agitation for 1 min and a final spin for 2 min) then immediate freezing at $-20^{\circ} \mathrm{C}$.

symbols in Figure 4) when large differences are evident. It is clear that none of the artificial techniques successfully replicated the changes observed when real boli were used. Because the results with real boli (processing method 6) were furthest away from the results with undamaged grass (processing method 1), the suggestion is that the bolus simulations failed because they did not damage the grass tissue as much as during the real processes of mastication and ingestion. This assertion is supported by visual examination of the extent of tissue damage in boli. However, it is not possible to argue that the extent of microbial colonization depends solely on the extent of tissue damage, because there was much less colonization and loss of herbage fatty acid from freeze-dried and ground samples (processing method 7). This latter observation appears to be in contrast to the fact that the highest DM degradation was observed with the freeze-dried and ground samples (processing method 7). One possible explanation for this discrepancy is increased loss of unfermented fine particles falling through the pores of the polyester bags when the grass has been dried and ground (Dewhurst et al., 1995), although it could also be explained by a more complex relationship between microbial colonization and DM disappearance.

The other observation from the PCA-biplot analyses is that there was not good agreement between duplicate incubations, particularly for some of the sample preparation methods used in experiment 1 . This probably reflects natural variation in the susceptibility of herbage to damage using these approaches.

With the exception of anteiso $\mathrm{C}_{15: 0}$, which was present in grass, the OBCFA behaved very similarly in these sets of samples. Consequently, it was not possible to use this approach to draw inferences about changes in the composition of the bacteria across these sample sets. It may be that use of a wider range of more distinctive minor fatty acids might permit this type of analysis. Studies with the soil microbial community have often employed 10 to 15 individual fatty acids to explain the distinctive differences among samples (Ibekwe and Kennedy, 1999; Steenwerth et al., 
2003). The major difference between LAB and SAB, for example, was levels of $\mathrm{C}_{18: 0}$, which is not distinctive to bacteria and could not provide discrimination in the present analysis. More detailed description of the microbial colonization of feeds will rely on use of molecular approaches, such as denaturing gradient gel electrophoresis (Kocherginskaya et al., 2001).

\section{Fatty Acid Biohydrogenation}

The PCA-biplot analysis also included cis-9, trans11 CLA and VA, which are major intermediates of fatty acid biohydrogenation in the rumen. Interestingly, these fatty acids behaved quite differently across both of the datasets (Figures 4 and 5). Vaccenic acid behaved very similarly to the OBCFA, but the pattern of change in CLA levels was intermediate to the patterns of change for plant fatty acids and microbial OBCFA.

The virtual absence of CLA in LAB and SAB samples (Table 2) and the pattern of variation of CLA suggest that it is produced in the extracellular matrix around bacteria, but not extensively incorporated. However, it remains possible that the production of CLA could be accomplished by a liquid-phase bacterial population that was not significantly represented in our LAB samples. In contrast, VA was present in bacterial samples (Table 2) and varied in the same way as other microbial fatty acids (Figures 4 and 5). This confirms the model envisaged by Hazlewood and Dawson (1979) in which plant fatty acids are converted to VA before being incorporated into bacterial lipids. Earlier studies of CLA production by different organisms have found situations in which CLA production is largely extracellular (Propionibacterium studies of Jiang et al., 1998), mainly intracellular (Lactobacillus studies of Ogawa et al., 2001), or both (Bifidobacterium studies of Oh et al., 2003). The latter study showed increased levels of intracellular CLA when bacteria were in the stationary phase.

\section{CONCLUSIONS}

The main OBCFA (with the exception of anteiso $\mathrm{C}_{15: 0}$ ) were not found in fresh grass and were useful markers of the effects of incubation time, sample preparation method, and washing method on microbial colonization/contamination. Although OBCFA were useful markers of the extent of microbial colonization, patterns of OBCFA did not reveal any further information about the types of bacteria colonizing herbage. Principal component analysis biplot analysis provided a good overall description of the processes of microbial colonization and degradation of plant fatty acids on fresh herbage incubated in the rumen. Bolus formation during mastication and ingestion results in extensive damage to herbage. None of the techniques (cutting, crushing, or drying/grinding) investigated in this work was able to replicate the effects of bolus formation in the animal in terms of effects on fatty acid profiles, suggesting that future work should focus on real boli. Biohydrogenation of the polyunsaturated fatty acids of fresh herbage was used principally by SAB to enable them to take up high levels of VA and $\mathrm{C}_{18: 0}$. Although VA was strongly associated with bacterial markers (OBCFA), its precursor (CLA) was not associated with bacterial variation, suggesting that its production in the rumen under these conditions was mainly extracellular. Consequently, great care must be taken to take account for liquid-phase processes in future studies of lipolysis and biohydrogenation.

\section{ACKNOWLEDGMENTS}

We are grateful to John Tweed for assistance with fatty acid analysis. The financial support of the Department for Environment, Food and Rural Affairs is gratefully acknowledged.

\section{REFERENCES}

Bauchart, D., F. Legay-Carmier, M. Doreau, and B. Gaillard. 1990. Lipid metabolism of liquid-associated and solid-adherent bacteria in rumen contents of dairy cows offered lipid-supplemented diets. Br. J. Nutr. 63:563-578.

Boudon, A., and J.-L. Peyraud. 2001. The release of intracellular constituents from fresh ryegrass (Lolium perenne L.) during ingestive mastication in dairy cows: Effect of intracellular constituent, season and stage of maturity. Anim. Feed Sci. Technol. 93:229-245.

Cabrita, A. R., A. J. Fonseca, R. J. Dewhurst, and E. Gomes. 2003. Nitrogen supplementation of corn silages. 2. Assessing rumen function using fatty acid profiles of bovine milk. J. Dairy Sci. 86:4020-4032.

Cherney, D. J. R., J. A. Patterson, and R. P. Lemenager. 1990. Influence of in situ bag rinsing technique on determination of dry matter disappearance. J. Dairy Sci. 73:391-397.

Dewhurst, R. J., R. T. Evans, N. D. Scollan, J. M. Moorby, R. J. Merry, and R. J. Wilkins. 2003. Comparison of grass and legume silages for milk production. 2 . In vivo and in sacco evaluations of rumen function. J. Dairy Sci. 86:2612-2621.

Dewhurst, R. J., D. Hepper, and A. J. F. Webster. 1995. Comparison of in sacco and in vitro techniques for estimating the rate and extent of rumen fermentation of a range of dietary ingredients. Anim. Feed Sci. Technol. 51:211-229.

Dewhurst, R. J., and M. R. F. Lee. 2005. Alternative strategies for manipulating milk fat in dairy cows. Pages $255-275$ in Recent Advances in Animal Nutrition. P. C. Garnsworthy, ed. Nottingham University Press, Nottingham, UK.

Diedrich, M., and K. P. Henschel. 1990. The natural occurrence of unusual fatty acids. 1. Odd numbered fatty acids. Nahrung 34:935-943.

Dzierzewicz, Z., B. Cwalina, S. Kurkiewicz, E. Chodurek, and T. Wilczok. 1996. Intraspecies variability of cellular fatty acids among soil and intestinal strains of Desulfovibrio desulfuricans. Appl. Environ. Microbiol. 62:3360-3365.

Fievez, V., B. Vlaeminck, M. S. Dhanoa, and R. J. Dewhurst. 2003. Use of principal component analysis to investigate the origin of 
heptadecenoic and conjugated linoleic acids in milk. J. Dairy Sci. 86:4047-4053.

Gabriel, K. R. 1971. The biplot graphic display of matrices with application to principal component analysis. Biometrika 58:453-467.

Hawke, J. C. 1973. Lipids. Pages 213-263 in Chemistry and Biochemistry of Herbage. U. W. Butler and R. W. Bailey, eds. Academic Press, London, UK.

Hazlewood, G., and R. M. Dawson. 1979. Characteristics of a lipolytic and fatty acid-requiring Butyrivibrio sp. isolated from the ovine rumen. J. Gen. Microbiol. 112:15-27.

Ibekwe, A. M., and A. C. Kennedy. 1999. Fatty acid methyl ester (FAME) profiles as a tool to investigate community structure of two agricultural soils. Plant Soil 206:151-161.

Jiang, J., L. Björck, and R. Fondén. 1998. Production of conjugated linoleic acid by dairy starter cultures. J. Appl. Microbiol. 85:95-102.

Jolliffe, I. T. 1986. Principal Component Analysis. Springer-Verlag, New York, NY.

Kingston-Smith, A. H., and M. K. Theodorou. 2000. Post-ingestion metabolism of fresh forage. New Phytol. 148:37-55.

Kocherginskaya, S. A., R. I. Aminov, and B. A. White. 2001. Analysis of the rumen bacterial diversity under two different diet conditions using denaturing gradient gel electrophoresis, random sequencing, and statistical ecology approaches. Anaerobe 7:119134.

Lawes Agricultural Trust. 2002. GenStat Release 7.1 Reference Manual. VSN International, Oxford, UK.

Lee, S. S., M. B. Chang, N. D. Scollan, R. J. Merry, M. S. Dhanoa, P. J. Hobbs, V. J. Theobald, W. J. Maeng, and R. J. Dewhurst. 1999. The fatty acid composition of solid- and liquid-associated rumen bacteria isolated from cows. Page 30 in Proc. Br. Soc. Anim. Sci., Scarborough, UK. Br. Soc. Anim. Sci., Edinburgh, UK.

Massart-Leen, A. M., and D. L. Massart. 1981. The use of clustering techniques in the elucidation or confirmation of metabolic pathways. Application to the branched-chain fatty acids present in the milk fat of lactating goats. Biochem. J. 196:611-618.
Merry, R. J., and A. B. McAllan. 1983. A comparison of chemical composition of mixed bacteria harvested from the liquid and solid fractions of rumen digesta. Br. J. Nutr. 50:701-709.

Meyer, J. H. F., and R. I. Mackie. 1986. Microbiological evaluation of the intraruminal in sacculus digestion technique. Appl. Environ. Microbiol. 51:622-629.

Ogawa, J., K. Matsumura, S. Kishino, Y. Omura, and S. Shimizu. 2001. Conjugated linoleic acid accumulation via 10-hydroxy-12octadecaenoic acid during microaerobic transformation of linoleic acid by Lactobacillus acidophilus. Appl. Environ. Microbiol. 67:1246-1252.

Oh, D.-K., G.-H. Hong, Y. Lee, S. Min, H.-S. Sin, and S. K. Cho. 2003. Production of conjugated linoleic acid by isolated Bifidobacterium strains. World J. Microbiol. Biotechnol. 19:907-912.

O'Kelly, J. C., and W. G. Spiers. 1991. Influence of host diet on the concentrations of fatty-acids in rumen bacteria from cattle. Aust. J. Agric. Res. 42:243-252.

Siddons, R. C., D. E. Beever, and J. V. Nolan. 1982. A comparison of methods for the estimation of microbial nitrogen in duodenal digesta of sheep. Br. J. Nutr. 48:377-389.

Steenwerth, K. L., L. E. Jackson, F. J. Calderon, M. R. Stromberg, and K. M. Scow. 2003. Soil community composition and land use history in cultivated and grassland ecosystems of coastal California. Soil Biol. Biochem. 35:489-500.

Sukhija, P. S., and D. L. Palmquist. 1988. Rapid method for determination of total fatty acid content and composition of feedstuffs and feces. J. Agric. Food Chem. 36:1202-1206.

Vanzant, E. S., R. C. Cochran, and E. C. Titgemeyer. 1998. Standardization of in situ techniques for ruminant feedstuff evaluation. J. Anim. Sci. 76:2717-2729.

Zelles, L. 1997. Phospholipid fatty acid profiles in selected members of soil microbial communities. Chemosphere 35:275-294.

Zhu, W. Y., A. H. Kingston-Smith, D. Troncoso, R. J. Merry, D. R. Davies, G. Pichard, H. Thomas, and M. K. Theodorou. 1999. Evidence of a role for plant proteases in the degradation of herbage proteins in the rumen of grazing cattle. J. Dairy Sci. 82:2651-2658. 